This is an Accepted Manuscript of an article published by Taylor \& Francis in Legal Reference Services Quarterly on May 16, 2016, available online: http://dx.doi.org/10.1080/0270319X.2016.1177422.

\title{
Preparing Law Students for Information Governance
}

\author{
SUSAN DAVID DEMAINE \\ Ruth Lilly Law Library, Indiana University Robert H. McKinney School of Law, Indianapolis, Indiana, USA \\ Information governance is a holistic business approach to managing and using \\ information that recognizes information as an asset as well as a potential source of \\ risk. Law librarians and legal information professionals are well situated to take \\ leadership roles in information governance efforts, including instructing law students \\ in information governance principles and practices. This article traces the \\ development of information governance and its importance to the legal profession, \\ offers a primer on information governance principles and implementation, and \\ discusses how academic law librarians and other legal educators can teach \\ information governance to law students using problem-based learning or similar \\ pedagogical methods. \\ KEYWORDS information governance, e-discovery, law school curriculum, practice-ready, \\ instruction, law librarian, legal education, information management, data, problem-based learning
}

In a world in which information is increasingly seen as a top-level asset, the safeguarding and management of information is of concern to everyone. ${ }^{1}$

\section{WHAT IS INFORMATION GOVERNANCE?}

\section{(C) Susan David deMaine}

The author would like to offer many thanks to the members of the 2015 Boulder Conference on Legal Information for their input and many improvements to this article, particularly Maria Protti, Benjamin J. Keele, and Catherine A. Lemmer. Special thanks also to Marguerite Most for her careful consideration and editorial input.

Address correspondence to Susan deMaine, Ruth Lilly Law Library, Indiana University Robert H. McKinney School of Law, 530 West New York Street, Indianapolis, IN 46202, USA, E-mail: sdemaine@iupui.edu 1 (2014). 
Information governance is a holistic business approach to information developed in response to the demands of electronic discovery in litigation, technological developments, exponential increases in data, privacy concerns, and the importance of information in business decisions. The essential idea of information governance is that information is an asset that, if managed wisely, has great value, but if managed poorly (or not at all), opens an organization up to serious risks. ${ }^{2}$ In its Commentary on Information Governance, the Sedona Conference ${ }^{3}$ defines information governance as an organization's "coordinated, interdisciplinary approach to satisfying information compliance requirements and managing information risks while optimizing information value.”4

Soon after the well-known Zubulake decisions by Judge Scheindlin in the Southern District of New York in the early 2000s marked a seismic shift in the discovery of electronic information for litigation, ${ }^{5}$ the experts of the Sedona Conference recognized that e-discovery was only part of the challenge. E-discovery could not be fully addressed without discussing the larger information environment. ${ }^{6}$

Since then, new knowledge, practices, and technologies have developed; so have expectations and demands. The fact that "the world contains an unimaginably vast amount of digital information which is getting ever vaster ever more rapidly" ${ }^{7}$ means the goalposts are always moving ahead. In addition, regulation of information has escalated in response to rising privacy, security, and financial stability concerns, and has created additional obligations for companies and the lawyers who advise them. Information governance is designed to anticipate and prepare for these data challenges so that crises can be avoided when possible, responses can be appropriate, efficient, and effective, and better business decisions can be made. Now, information governance is a matter of necessity for the firms and organizations in which lawyers work and, perhaps more importantly, for the clients that lawyers advise. Information governance

2 The risks reduced by information governance are more than just legal or security risks. They also include enterprise risks such as lost business opportunities or unforeseen changes in an organization's market.

3 The Sedona Conference is a nonprofit institute "dedicated to the advanced study of law and policy in the areas of antitrust law, complex litigation, and intellectual property rights. The mission of [the Sedona Conference] is to drive the reasoned and just advancement of law and policy by stimulating ongoing dialogue amongst leaders of the bench and bar to achieve consensus on tipping point issues." About Us, SEDONA CONFERENCE, https://thesedonaconference.org/aboutus [http://perma.cc/DW8K-NF5C]. It is well-known for its work on e-discovery best practices, among other things.

4 SEDONA CONFERENCE, COMMENTARY ON INFORMATION GOVERNANCE 4 (Dec. 2013), https://thesedonaconference.org/publication/The $\% 20$ Sedona $\% 20$ Conference $\%$ C2 $\%$ AE $\% 20$ Commentary $\% 20$ on $\% 20 I$ nformation\%20Governance [http://perma.cc/ZP7P-KH9M].

5 The decisions in Zubulake v. USB Warburg in the early 2000 s shifted some of the costs of retrieving electronically stored information (ESI) to the requesting party but left $75 \%$ of the costs to be borne by the responder and imposed heavy sanctions for the loss of such information. See Zubulake v. UBS Warburg LLC, 217 F.R.D. 309 (S.D.N.Y. 2003) (Zubulake I); Zubulake v. UBS Warburg LLC, 216 F.R.D. 280 (S.D.N.Y. 2003) (Zubulake III); Zubulake v. UBS Warburg LLC, 220 F.R.D. 212 (S.D.N.Y. 2003) (Zubulake V).

6 SEDONA CONFERENCE, supra note 4, at 4.

7 Data, data everywhere, ECONOMIST, Feb. 25, 2010, at 71, available at http://www.economist.com/node/15557443 [http://perma.cc/LMW2-E6C5]. 
has become "table stakes," essential not only to e-discovery and compliance but also to business success and security.

Law librarians and legal information professionals are positioned at the crossroads of information science, law, business, and education, and thus we are uniquely situated to make significant contributions to information governance. ${ }^{8}$ This article explores how academic law librarians can seize opportunities to help prepare law students for information governance. Many law schools have responded to the rapid development of e-discovery by offering specialized courses, ${ }^{9}$ but only a few address the larger topic of information governance. Information governance's relationship to e-discovery and other legal concerns such as regulatory obligations and business practices makes familiarity with information governance vital for lawyers advising clients in these areas. Although there is little room in most law school curricula for extensive study of business management trends, lawyers should understand what the business community is doing and be able to talk knowledgably on the subject.

This article offers a primer on information governance for law librarians and other legal educators who want to understand the rising importance of information governance (Parts II through V). It then discusses the importance of and methods for teaching law students about information governance (Parts VI and VII).

\section{WHY INFORMATION GOVERNANCE NOW?}

The concept of information governance has been around since businesses began using computers for everyday activities, ${ }^{10}$ but it has become a pressing issue in the last several years thanks to a convergence of events. The first is e-discovery. Over the last two decades, discovery has shifted from production of mostly paper documents to production of vast quantities of electronic information (referred to in the field as ESI, or electronically stored information). ESI can include emails, texts or other instant messages, calendars, documents, spreadsheets, databases, presentations, research data compilations, and so on. Responding to ediscovery requests for all this data can be disruptive, difficult, and expensive. A large portion of the disruption and expense can be chalked up to two main factors: dealing with information that was unnecessarily retained, and accessing information that was not well-preserved. Furthermore, even "deleted" ESI can sometimes be recovered and its production required in the discovery process.

E-discovery was in its nascent stages in 2003 when Judge Scheindlin of the U.S. District Court for the Southern District of New York issued several pre-trial decisions in Zubulake v. UBS Warburg, a case

8 In an email to an American Association of Law Librarians (AALL) discussion group, Jean O'Grady asserted that it is time for law librarians "to claim leadership of the broader universe of legal information...." We need to be "identified with the broader executive leadership functions related to information and knowledge strategy" if we want to stop the trend that "[l]aw firms seek professionals from other disciplines to lead knowledge strategy." E-mail from Jean O'Grady, Dir. Research Serv. and Lib., DLA Piper, to AALL Association for Legal Information Discussion List (Jan. 11, 2016) (on file with author).

9 Michele Lange, Back to (Law) School: Ediscovery Education by the Numbers, EDISCOVERY BLOG (Sept. 3, 2014), http://www.theediscoveryblog.com/2014/09/03/back-law-school-ediscovery-education-numbers /

[http://perma.cc/2J6U-93PZ]. Kroll's research found that 69 law schools were offering some level of instruction on ediscovery outside the typical Civil Procedure class. Unfortunately, the flip side of this number means that 124 schools are not offering stand-alone e-discovery instruction.

10 Some would posit that it has been around as long as filing cabinets and libraries. 
involving a workplace sex discrimination and retaliation claim. In a string of landmark opinions, Judge Scheindlin tackled e-discovery issues of first impression. In Zubulake $I^{11}$ and $I I I,{ }^{12}$ she crafted and applied a new test for cost-shifting when ESI is deemed “inaccessible.” Judge Scheindlin's approach required extensive and accurate information about the responding party's computer systems and data storage. In the end the responding party undertook extensive data recovery efforts to produce the "inaccessible" data and bore $75 \%$ of the related costs. In Zubulake $V^{13}$, Judge Scheindlin found that the defendant, its in-house counsel, and its outside counsel all failed in their duties to preserve relevant evidence once litigation was reasonably anticipated. She sanctioned them all, including the lawyers. ${ }^{14}$

These decisions and other developments in e-discovery had an impact on the 2006 amendments to the Federal Rules of Civil Procedure. ${ }^{15}$ The amendments specifically included ESI as discoverable, increased involvement by the courts in the discovery process, and added to early disclosure and discussion requirements. They also provided a safe harbor when spoliation was truly inadvertent and offered some protection against inadvertent disclosure of privileged materials. ${ }^{16}$

More than a decade after the Zubulake decisions and a decade after the 2006 amendments to the Federal Rules of Civil Procedure, many attorneys still do not understand the nuts and bolts of e-discovery and its implications. ${ }^{17}$ Predictive coding, in which a sample of hand-picked relevant documents are used to "teach" computer software to identify other potentially relevant documents, is seldom understood or used despite evidence that it is more effective and less costly than other search methods. With phenomena such as cloud storage, bring-your-own-device policies, and social media, the challenges involved in e-discovery are growing considerably faster than the knowledge of many attorneys. ${ }^{18}$ Lack of knowledge can be costly. Failing to preserve data and to collect potentially relevant ESI can result in sanctions (monetary penalties and/or adverse rulings) for both client and counsel.

The complexities of e-discovery are not the only catalyst driving information governance. Ediscovery's breakout converged with increased regulation and data collection in several key areas. First,

\footnotetext{
11 Zubulake v. UBS Warburg LLC, 217 F.R.D. 309 (S.D.N.Y. 2003) (Zubulake I).

12 Zubulake v. UBS Warburg LLC, 216 F.R.D. 280 (S.D.N.Y. 2003) (Zubulake III).

13 Zubulake v. UBS Warburg LLC, 220 F.R.D. 212 (S.D.N.Y. 2003) (Zubulake V).

$14 \quad$ See id.

15 Judge Scheindlin was a member of the Judicial Conference of the United States Advisory Committee on the Federal Rules of Civil Procedure from 1998 to 2005, when the committee was drafting the 2006 amendments to the Federal Rules of Civil Procedure.

16 See Fed. R. Civ. P. Rules 16, 26, 33, 34, 37, and 45 (as amended 2006). See also Carl G. Roberts, The 2006

Discovery Amendments to the Federal Rules of Civil Procedure, LAW PRAC. TODAY (Aug. 2006), http://apps.americanbar.org/lpm/lpt/articles/tch08061.shtml [http://perma.cc/3MT3-27SA].

17 Ed Silverstein, Survey: Attorneys Don't Know Enough E-Discovery, LEGALTECH NEWs (Feb. 17, 2015), http://www.legaltechnews.com/home/id=1202718079925/Survey-Attorneys-Dont-Know-Enough-EDiscovery [http://perma.cc/3MT3-27SA].

18

Id.
} 
the passage of the USA PATRIOT Act ${ }^{19}$ in the wake of the 9/11 terrorist attacks greatly increased the collection of data by the government. Accounting scandals at Enron and Worldcom prompted passage of the Sarbanes-Oxley Act of 2002, ${ }^{20}$ which created new record-keeping and reporting compliance measures. The financial crisis of 2008 led to the Dodd-Frank Wall Street Reform and Consumer Protection Act ${ }^{21}$ under which financial institutions are subject to more data collection, retention, and reporting requirements. Regulations protecting consumer privacy such as the Federal Trade Commission's Safeguards Rule ${ }^{22}$ in 2002 and Red Flags Rule ${ }^{23}$ in 2007 have also caused proper data collection, handling, and storage to become issues of utmost importance. It is estimated that "[i]n the U.S. alone,...there are more than 20,000 laws that deal with how long data is kept and what form it is in." 24

Complicating matters is the fact that data crosses national boundaries without pause or notice. With internet connectivity and cloud computing, data can travel the globe instantaneously, touching servers in many different jurisdictions. People also travel, of course, and it is not always clear whether they carry the protections of their home country with them or are subject to the protections of the host country. The European Union, for example, has extensive laws governing data, especially personal data, ${ }^{25}$ as do many other countries. ${ }^{26}$ But many do not. The complexities are staggering.

The sheer amount of data being generated as the digital age continues to unfold is another complication. Governments, businesses, organizations, and individuals are producing, using, and collecting ever

19

20 Pub. L. 107-204, 116 Stat. 745 (July 30, 2002), codified at 15 U.S. Code $\int 7201$ et seq.

21 Pub. L. 111-203, 124 Stat. 1376 (July 21, 2010), codified at 12 U.S. Code $\int 5301$ et seq.

22 16 C.F.R. 314.1-314.5 (2015). This rule requires financial institutions subject to the jurisdiction of the Federal Trade Commission to establish data security protocols and systems to protect consumer data. These financial institutions must also ensure that their affiliates and service providers keep consumer data secure.

2316 C.F.R. 681.1 (2015). This rule requires many businesses to establish and implement a written identity theft prevention program to help detect warnings of a data security breach and theft of identity information.

24 Rebekah Mintzer, Build a Better Information Governance Program, LEGALTECH NEWs (Feb. 5, 2015), http://www.legaltechnews.com/id=1202717053709 [http://perma.cc/55Y2-L8LY].

25 See generally, Dorothee Heisenberg, Negotiating Privacy: The European UniOn, THE United States, and Personal Data Protection (2005); Julia M. Fromholz, The European Union Data Privacy Directive, 15 BERK. TECH. L.J. 461 (2000); Christopher Kruner, The European Union and the Search for an International Data Protection Framework, 2 GRONINGEN J. INT'L L. 55 (2014) (discussing the EU's interest in promoting its own data protection laws as well as data protection on a global scale).

26 See Charles R. Ragan, Information Governance: It's a Duty and It's Smart Business, 19 RICH. J.L. \& TECH. 12, \11-15 (2013) (citing Gail Lasprogata et al., Regulation of Electronic Employee Monitoring: Identifying Fundamental Principles of Employee Privacy through a Comparative Study of Data Privacy Legislation in the European Union, United States and Canada, 2004 STAN.

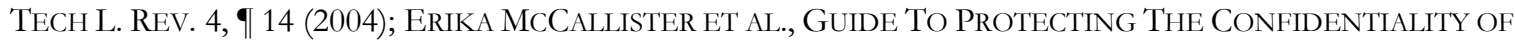
Personally Identifiable Information \2-2 (2010); Matthew Glynn, Australia: Data Privacy Compliance in Asia Pacific, MONDAQ (Nov. 17, 2012), http://www.mondaq.com/australia/x/206518/data+protection/data+privacy+compliance+in +asia+pacific [http://perma.cc/P3Y7-D5L5]; and Aldo M. Leiva, Data Protection Law in Spain and Latin America: Survey of Legal Approaches, 41 INT'L L. NEWS, Fall 2012, at 1. 
increasing amounts of information. Big data ${ }^{27}$-immense amounts of data being created very rapidly and in all sorts of formats ${ }^{28}$ - has entered the scene. With tremendous growth in online shopping, social media, mobile devices, and the "internet of things," we are experiencing an explosion of digital data with no end in sight. ${ }^{29}$ Research conducted by IBM indicates that by the end of 2011, "everyday consumers [were] creating 2.5 quintillion bytes [2.5 billion gigabytes] of data." ${ }^{30}$ Of course, that figure is now several years out of date, and it is estimated that the amount of digital information increases tenfold every five years. ${ }^{31}$

The effects of the interwoven and immense growth in data, laws, and e-discovery expectations have been exacerbated by corporate data breaches such as those experienced by Anthem, Target, and Sony Pictures. ${ }^{32}$ Other data scandals such as Hilary Clinton's use of a personal email server when she served as Secretary of State have added to an atmosphere of fear regarding out-of-control data. ${ }^{33}$ These events highlight the need for consistent information governance policies.

The current interest in information governance in the corporate world and legal profession results from this convergence of massive increases in the amount of data with more obligations to track and protect data, more need to pluck data from the haystacks when necessary, and more push to make data-driven business

27 Big data is regularly identified as big in three dimensions: volume, velocity, and variety. Doug Laney, 3-D Data Management: Controlling Data Volume, Velocity and V ariety, GARTNER (Feb. 6, 2001), http://blogs.gartner.com/douglaney/files/2012/01/ad949-3D-Data-Management-Controlling-Data-Volume-Velocity-and-Variety.pdf [http://perma.cc/5UQZ-US9K]. See also Doug Laney, Deja VVVu: Others Claiming Gartner's Construct for Big Data, GARTNER (Jan. 14, 2012), http:/ / blogs.gartner.com/doug-laney/deja-vvvue-others-claiming-gartners-volume-velocityvariety-construct-for-big-data/ [http://blogs.gartner.com/doug-laney/deja-vvvue-others-claiming-gartners-volumevelocity-variety-construct-for-big-data/]. To get an idea of what big data refers to, consider all clicks Amazon's computers record every day, all the tweets that are sent, the pings from all the smartphones, and a day's worth of data produced by the Large Hadron Collider. A car manufacturer might have big data in the data recorded by all its testing equipment or data sent in from vehicles on the road, while a city might have big data in its traffic camera records. "Data mining" means finding ways to extract useful information out of the billions of data points being collected.

28 Data scientists distinguish between structured data and unstructured data. Classic databases offer structured data, with row and header columns, formulae, labels, and meticulous metadata. The data gathered from email, social media, the internet of things, and elsewhere varies so widely in format and content that it is simply called unstructured data.

29 Data, data everywhere, supra note 7.

30 IBM Study Reveal Challenges Midmarket CMOs Face to Sustain Brand Loyalty with Today's Social Consumer, IBM NEWS RELEASES (Nov. 16, 2011), http://www-03.ibm.com/press/us/en/pressrelease/35999.wss [http://perma.cc/ALT33QWG].

$31 \quad$ Id.

32 Erin E. Harrison, InfoGov: Not Just Another Pretty Buzzword, LEGALTECH News (June 1, 2015), http://www.legaltechnews.com/id=1202727858316 [http://perma.cc/JP2X-MLVE]. See also SEDONA CONFERENCE, supra note 4 , at 2 .

33 Michael S. Schmidt, Hillary Clinton Used Personal Email Account at State Dept., Possibly Breaking Rules, N.Y. TIMES (March 2, 2015), http://www.nytimes.com/2015/03/03/us/politics/hillary-clintons-use-of-private-email-at-statedepartment-raises-flags.html [http://perma.cc/ZUE8-J8M9 ]. A version of this article also appeared in print at Michael S. Schmidt, Clinton Used Personal Email at State Dept., N.Y. TIMES, March 3, 2015, at A1. 
decisions. This is evidenced in guidelines coming from records management associations, ${ }^{34}$ e-discovery vendors and advisors, ${ }^{35}$ information technology consultants, ${ }^{36}$ and those who specialize in law and technology. ${ }^{37}$

\section{WHAT DOES INFORMATION GOVERNANCE DO?}

It would be hard to overstate the importance of information and the knowledge we can derive from it, but understanding, protecting, and making the most of the vast quantities of information we are producing takes planning and strategic thinking. Management of information has typically been siloed into departments such as IT (hardware and software, storage, security), records (regulatory compliance, retention), marketing (customer data), library (research, external information sources, knowledge databases), and legal (litigation holds, e-discovery). Information governance cuts across these siloes and sees information first and foremost as a business asset. To derive the most value from this asset, the resources and processes needed to create, use, and protect the information must be understood and appropriately designed. These two foci-(1) business value and (2) resources and processes-present no small task. The necessary resources and processes are numerous and complex. Understanding the business value of information requires simultaneous consideration of opportunity and risk, both of which can be difficult to identify and measure. ${ }^{38}$

To be successful, information governance must address data through its entire lifecycle-from creation, use, retention, and destruction-before they arise. Unlike information management strategies of the past, no single silo is the focus. Instead, overall productivity and value are the goals. ${ }^{39}$ Information governance envisions an entire framework of policies, procedures, technologies, organizational systems and enforcement mechanisms that bring about reliable compliance by all participants in the enterprise. ${ }^{40}$ This framework can be built from the answers to the following questions as applied to all sorts of different information:

1. Use: What is the information for? What information is required? Is this the right information for the task?

2. Flow: Where is information coming from and where is it going?

3. Timing: When is the information needed?

\footnotetext{
34 See, e.g., ARMA International, http://www.arma.org/ [http://perma.cc/4HXR-S2PU].

35 See, e.g., The Sedona Conference, https://thesedonaconference.org/ [http://perma.cc/DW8K-NF5C].

36 See, e.g., Gartner Inc., http://www.gartner.com/technology/home.jsp [http://perma.cc/ACE5-DY7E].

37 See, e.g., Legaltech News, which frequently publishes articles on information governance at its website.

Information governance is also being covered at legal technology conferences. See, e.g., Ed Silverstein, Legaltech West Panel to Ready Organizations for Infogov Explosion, LEGALTECH NEWs (May 21, 2015), http:/ /www.legaltechnews.com/latestnews/id=1202727128163/Legaltech-West-Panel-to-Ready-Organizations-for-Infogov-Explosion [http://perma.cc/9SX9-9NGG].

$38 \quad I d$.

$39 \quad$ Vasant Raval and Greg Dyche, Seven Myths of Information Governance, 4 ISACA J., Aug. 2012, at 26.

40 See Amelia Phillips et al., E-Discovery: An Introduction to Digital Evidence 41-42, 175-77 (2014); LINDA VOLONINO AND IAN REDPATH, E-DisCOVERY FOR DUMMIES 240-49 (2010).
} 
4. Access: Who can and should be using the information and for what purpose?

5. Interaction: How do users manipulate/interact with the information?

6. Compliance: What social and legal obligations are attached to the information?

7. Risk: What happens if this information is leaked or stolen or misused?

8. Retention/destruction: What is the useful life of the information?

9. Responsibility: Who is/should be accountable for the information? ${ }^{41}$

The result is a system that distinguishes between different kinds of information based on importance to the business, usefulness, obligations, and longevity, and provides for the storage and use of that information. The information governance system can then anticipate e-discovery and be prepared for litigation holds. It also ensures that there are destruction policies and technologies in place so that information can be deleted once its useful lifespan is over. It incorporates compliance, privacy, and security considerations. Finally, an effective information governance system provides for information recovery in the wake of disaster by backing up essential data. By viewing the many facets of information as a whole, planning for the total life of the information is more effective and valuable than if planning is done piecemeal.

To appreciate the effects of information governance, consider more closely the matter of e-discovery. As discussed above, ${ }^{42}$ information governance owes its development, in part, to the explosive growth in ediscovery and therefore is designed in part to address complexities of e-discovery. ${ }^{43}$ The overarching importance of information governance relative to e-discovery is explained by Linda Luperchio, Director of Information Lifecycle Governance and E-discovery at The Hanover Insurance Group:

[Information] governance expertise is as critical, if not more critical, than e-discovery expertise. If you don't approach...governance in the right way, the volume of work regarding e-discovery is going to go off the charts. Data grows at an alarming rate, so you have to get a handle on it as early as possible. ${ }^{44}$

Information governance helps with many of the tasks involved in e-discovery. For example, a data map is a useful tool for creating a shared understanding of data types and locations e-discovery. A data map can identify all the IT systems (including legacy systems ${ }^{45}$ ) and what they hold, back-up and retention policies,

41 The questions are derived from Christian P. Walker, Principles of Holistic Information Governance, The Info Gov Guerrilla (Apr. 1, 2013), https://christianpwalker.wordpress.com/2013/04/01/principles-of-holistic-informationgovernance/ [http://perma.cc/4WYF-GVC7].

42 See supra Part II.

43 It has also been posited that techniques used in e-discovery, such as predictive coding, can inform information governance — and be a valuable part of the expertise lawyers provide for their clients. See Bennett B. Borden and Jason R. Baron, Finding the Signal in the Noise: Information Governance, Analytics, and the Future of Legal Practice, 20 RICH. J.L. \& TECH. 7 (2014).

44 Chris DiMarco, Strong Info Governance Policies Can Drive Down E-Discovery Expenditure, LEGALTECH NEWs (March 9, 2015), http:/ / www.legaltechnews.com/id=1202720029692/Strong-Info-Governance-Policies-Can-Drive-DownEDiscovery-Expenditure [http://perma.cc/F3CT-G8HF].

45 "Legacy systems" are technologies that are no longer used (e.g. floppy disks or an old email server). Even though no longer used, the outdated technology may contain data relevant to current business activities or litigation. 
and who is responsible for these systems and policies. ${ }^{46}$ A data map is much easier to create - and hopefully already exists - if information governance is in place. Because information governance provides for all aspects of the information lifecycle, including discovery in litigation, an information governance plan will also ease the implementation of litigation holds, data collection, winnowing for relevance, review for privilege, and then production. Finally, information governance helps defend the destruction of data through the routine application of standard policies.

The role of e-discovery and other information functions in the larger information governance picture is illustrated by the Information Governance Reference Model (IGRM). The IGRM was developed by EDRM, a group of electronic discovery experts who originally created the well-known Electronic Discovery Reference Model. ${ }^{47}$ The IGRM is intended to illustrate and inform the discussion of information governance and continues to be tweaked as insights arise. The IGRM serves as a visual means of understanding what people mean when they talk about information governance. It is not intended to be prescriptive but rather "to provide a reference that will promote cross-functional dialogue and collaboration.” 48

46 For more on data maps and IG, see Information Maps: A Multi-Disciplinary Must, IrON MOUNTAIN, http://www.ironmountain.com/ /media/Files/Iron\%20Mountain/Knowledge\%20Center/Reference\%20Library/Whi te $\% 20$ Paper/I/Information $\% 20$ Maps $\% 20 \% 20 \mathrm{~A} \% 20 \mathrm{Multi} \% 20$ Disciplinary $\% 20 \mathrm{Must}$.pdf?dmc $=1 \&$ ts $=20150611 \mathrm{~T} 09522$ 27325 [http:/ / perma.cc/QN2F-FMLQ] (last visited June 11, 2015).

47 The Electronic Discovery Reference Model (EDRM) is a conceptual portrayal of the iterative stages of the ediscovery process. These stages include information governance, identification, preservation, collection, processing, review, analysis, production, and presentation. See EDRM Stages, EDRM, http://www.edrm.net/resources/edrm-stagesexplained [https://perma.cc/U6BV-NWF4].

48 Information Governance Reference Model, EDRM, http://www.edrm.net/projects/igrm [http://perma.cc/X43MUNPK]. 


\section{Information Governance Reference Model (IGRM)}

Linking duty + value to information asset = efficient, effective management

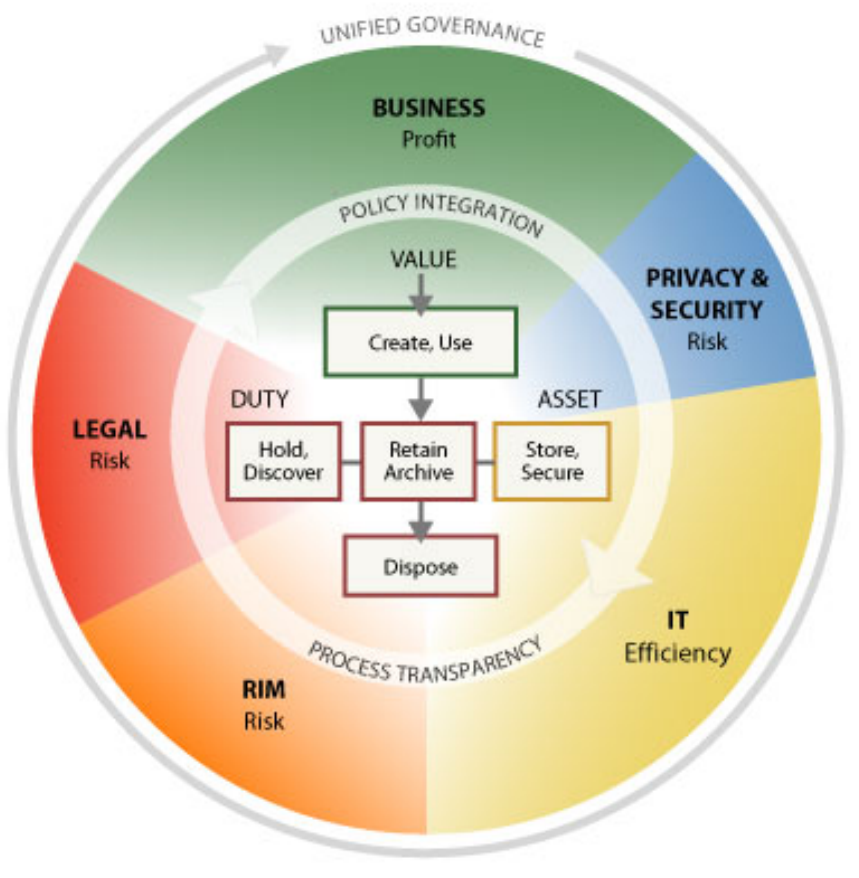

Duty: Legal obligation for specific information
Value: Utility or business purpose of specific information
Asset: Specific container of information

Fig. 1: The IGRM Model. Used with persmission.

The outer ring of the IGRM shows the entities within an organization that have responsibility for and interest in information at some point during the information's lifecycle. Briefly, Business is concerned with the development and application of information. Legal and Records/Information Management (RIM) are concerned with identifying, organizing, and retaining information for compliance purposes, legal protections of value, and responses to litigation. IT is concerned with implementing and maintaining access, storage, and retrieval systems. Closely related to IT is Privacy/Security, which is concerned with protecting information from theft and corruption. Together, IT and Privacy/Security likely bear responsibility for disaster recovery as well. ${ }^{49}$ Depending on the nature and size of the organization, boundaries between these

49 Recovering from a natural disaster or something similarly devastating is typically the impetus behind the planning, but a security breach is actually more likely. A recovery plan should be part of information governance structure. In another example, banks and financial institutions are expected to have recovery plans to restore their 
entities may be blurred or even nonexistent, and distinctions may arise more from how information is viewed than from which department is doing the viewing.

The center of the diagram illustrates the basic lifecycle of information as it moves from creation and use in the business sector of the model through retention to eventual disposal. Notice that during the middle stage, the need for litigation holds and discovery falls in the purview of the legal sector while storage and security are handled at the intersection of the IT and privacy/security sectors. Disposal falls into the RIM and IT sectors as it is often RIM that identifies information that is no longer needed and IT ensures proper disposal.

The inner and outer circular arrows of the diagram emphasize that information governance is holistic, ongoing, and unified - an approach to information that requires integration of policies and transparency of process throughout the governance structure.

\section{HOW DOES INFORMATION GOVERNANCE RELATE TO AND DIFFER FROM OTHER INFORMATION MANAGEMENT SCHEMES?}

Organizational and information experts employ a slew of acronyms and terms to talk about coping with information. In addition to information governance, these include governance of information technology (IT governance), information management, records (and information) management (RIM), knowledge management (KM), enterprise content management (ECM), and big data analytics. The distinctions between information governance and other information management models are an important part of the shared vocabulary that contributes to information governance's success. ${ }^{50}$ Without this background knowledge, people may well resist the idea of information governance and see it as duplicative of other systems or just another trend. Communicating that information governance is an overarching, systemic goal different from other schemes is vital.

Because it is intended to cover the entire lifecycle of information in all parts of the organization, information governance is generally viewed as the most expansive of the information management schemes. The focus is on enterprise-wide strategy and policy covering everything from incoming data and analytics to storage and search, security and privacy, retention and deletion. A few voices maintain that information governance is actually narrower than it claims to be because it insists on "governing" and categorizing information, more like the compliance- and control-focused records management systems. ${ }^{51}$ According to one e-discovery attorney, this characterization of information governance is especially true now with the seas of information so vast—and expanding exponentially—-that governing it is infeasible. ${ }^{52}$

financial soundness and business operations in the event of financial disaster. See Luca Amorello and Sacha Huber, Recovery Planning: A New V aluable Corporate Governance Framework for Credit Institutions, 3 L. \& ECON. YEARLY REV. 296 (2014), available at http:// ssrn.com/abstract=2577760 [http://perma.cc/6UVW-ZXPV].

$50 \quad$ On the importance of shared vocabulary, see Mintzer, supra note 24.

51 See, e.g., Ralph Losey, Information Governance v. Search: The Battle Lines Are Redrawn, E-DisCOVERY TEAM (Feb. 8, 2015), http:/ /e-discoveryteam.com/2015/02/08/information-governance-v-search-the-battle-lines-are-redrawn/ [http://perma.cc/9JPS-RVKW]. 
To understand the extent of information governance, it helps to contrast it with the other schemes for managing information. While it may seem like little more than semantics, "information management" generally refers to an approach that emphasizes tactics and targeted procedures rather than information governance's enterprise-wide strategy and focus on information as an array of assets. Likewise, "enterprise content management" sounds like it has the scope of information governance, but pundits describe ECM as concentrating on documents rather than data. ECM views documents as having a defined purpose according to content rather than multi-faceted expressions of data with untapped potential value. ${ }^{53}$ ECM has also been described as a noun rather than a verb, the implication being that it is a static event and not an ongoing process that changes as technologies and information change. ${ }^{54}$

"Records management" concentrates on the organization and retention of information required for internal functions or by external bodies. This covers areas such as human resources, financial records and filings, product testing, supply chains certifications, and the like. Records management tends to focus on strict organizational systems, retention schedules, and destruction of material no longer needed.

"Knowledge management” focuses on the capture and sharing of work products, innovative ideas, insights, and lessons learned from experience. Knowledge management is concerned with collecting and curating information with high business utility. As defined early on in the KM movement, "[k]nowledge management is the process of capturing, distributing, and effectively using knowledge." 55 The emphasis is on sharing information in order to make better business decisions, streamline an organization's production, and avoid re-inventing the wheel. Examples include building databases of work products, identifying and developing experts, and creating communities of practice. ${ }^{56}$ Typically, knowledge management does not relate to e-discovery (either in its anticipation or implementation), management of information for compliance purposes, or enterprise-wide retention, destruction, privacy, and security issues.

"Big data" is data that is too large and diverse to handle on ordinary computing platforms with the usual business software. Gartner, the technology research and advising company, coined the often used 3Vs definition: data that is huge along three metrics—volume, velocity, and variety. ${ }^{57}$ In other words, big data is generated at unprecedented speeds and in numerous formats from multiple sources. Big data analytics are the methods and tools used to extract useful information from the enormous pools of data that are developing as digital technology becomes more ubiquitous. An attraction of big data analytics is the idea that information does not have to be well-organized to be workable; tools can be developed to mine vast

53 Dave Hunt, Where Worlds Collide - Why Enterprise Content Management is not Information Governance, BARRACUDA (Feb. 2, 2015), https://blog.barracuda.com/2015/02/02/where-worlds-collide-why-enterprise-content-management-isnot-information-governance/ [http://perma.cc/XL85-CB3R].

54 John Mancini, Content Management 2020: Thinking Beyond ECM (2015), available at http://info.aiim.org/cm2020 [http://perma.cc/2BY7-RL7U].

55 Thomas H. Davenport, Saving IT's Soul: Human Centered Information Management, HARV. Bus. REV., Mar.-Apr. 1994 , at 119.

56 Michael E. D. Koenig, What is KM? Knowledge Management Explained, KM WorLD (May 4, 2012), http://www.kmworld.com/Articles/Editorial/What-Is-.../What-is-KM-Knowledge-Management-Explained-82405.aspx [http://perma.cc/B74Q-KNYM].

$57 \quad$ Laney, Deja VVVu, supra note 27. 
and heterogeneous pools of data and still come up with useful results. ${ }^{58}$ It has been suggested that perhaps big data analytics will render moot the notion of proportionality in discovery. ${ }^{59}$ The notion of proportionality is currently intended to limit the scope and volume of document review in order to keep the cost of discovery from exceeding the value of the claim. Big data tools such as predictive coding are making massive searches much more feasible. ${ }^{60}$

It is impossible to know exactly how big data analytics will evolve, but it is not the same as information governance. Where information governance is a strategic approach to and understanding of all information needs and uses in the enterprise, big data analytics is a category of tools that can be used within the information governance structure to improve the use of information assets.

The term "data governance" is also evident in the literature. Sometimes this term is used to mean essentially the same thing as information governance. ${ }^{61}$ At other times, the term is used more narrowly, focusing on the nature and integrity of the data artifacts themselves rather than the knowledge they represent.

Information governance and IT governance are also different concepts. Technology is key to all information management systems. It is both the cause of and cure for the data explosion. With so many applications, so many devices, and so many heterogeneous data environments, information technology departments can feel overwhelmed. As IT expert Chris Curran writes, "IT is stressing under the weight of applications, emerging tech, vendors and systems and sans the support of a seamless, flexible and sturdy integrated infrastructure.”62 IT governance focuses on managing hardware and software resources to help alleviate the stress. Information governance includes IT governance but at the same time looks beyond the

58 Despite the excitement surrounding big data, the analytics have limitations that are sometimes unrecognized. Economist Tim Harford points out that a statistical problem such as a sampling error or a sampling bias is not resolved by big data but rather magnified. As an example, consider all the data produced by Twitter users. It is a remarkably large data pool, and would thereby suggest greater statistical accuracy by virtue of the large sample size. The problem is that Twitter users are not representative of the population as a whole; the sample is not random. Similarly, very large data sets can make flukes seem more prominent than they really are. Statisticians and computer scientists are working on new techniques to address some of the issues with big data. Tim Harford, Big data: Are we making a big mistake?, FIN. TIMES (Mar. 28, 2014), http://www.ft.com/cms/s/2/21a6e7d8-b479-11e3-a09a-00144feabdc0.html [http://perma.cc/2J975RYD].

59 James Shook, Vendor Voice: Will Big Data Eat Proportionality?, LEGALTECH News (Jan. 22, 2015), http://www.legaltechnews.com/id=1202715843471/Vendor-Voice-Will-Big-Data-Eat-Proportionality? [http://perma.cc/6QHP-U6XU].

60 See generally Borden and Baron, supra note 43.

61 See generally Kristin Weber et al., One Size Does Not Fit All--A Contingency Approach to Data Governance, 1 ACM J. DATA \& INFO. QUAL., June 2009, Art. 4, http:/ / dx.doi.org/10.1145/1515693.1515696.

62 Chris Curran, Understanding IT Complexity, CIO DASHBOARD (June 2, 2015), http://www.ciodashboard.com/itstrategy/understanding-it-complexity/ [http://perma.cc/MBY4-2U5S]. 
hardware and software to the content of the data and the information that can be pulled from it to determine its use and handling. ${ }^{63}$

\section{HOW DO BUSINESSES MAKE INFORMATION GOVERNANCE HAPPEN?}

As noted above, the IGRM is primarily a tool to help people talk about information governance. Building a shared understanding about information's value, use, and risk is vital because organizations can be overwhelmed by the idea of establishing information governance. They are paralyzed by the quantities of unmanaged information that can cost them dearly. To counter this paralysis, it is important to understand that information governance is an ongoing journey, not a destination. Policies, procedures, and decisions will need regular monitoring, further development, and tweaking. ${ }^{64}$

It is also important to understand what may help or hinder information governance. Paul Tallon, a professor of information systems, has identified organizational factors that enable or inhibit information governance. Factors that enable information governance include:

1. An organizational strategy that focuses on customers and innovations;

2. Technology strategies that align with customer/innovation focus and call for specific behaviors;

3. A centralized organization with centralized IT;

4. Standardization and integration of IT systems;

5. A culture that promotes strategic use of information;

6. Being subject to regulations that specify requirements for collection/retention; and

7. An awareness of accelerating data growth.

Factors that inhibit information governance include:

1. Product complexity and a broad product mix;

2. Outdated departmental silos (IT and others) and low process integration;

3. Pack-rat mentality in the organizational culture; and

4. Decentralization. ${ }^{65}$

To see these factors in action, consider two examples. First, take a large university comprised of many separate schools - everything from the fine arts to medicine. This organization must cope with a vast range of information: grades, class schedules, websites, personal and medical data, parking systems, payroll and benefits, financial data, library systems, research data of all sorts, and, last but not least, email. Traditionally, universities are relatively siloed organizations - the School of Liberal Arts needs one system while the School of Engineering needs another. Faculty members have a sense of independence unique to academia, and students come and go. There may be a culture that promotes hanging on to data forever (albeit sometimes for good reason). At the same time, however, IT is likely to be largely centralized, and the university culture is likely to support innovation as well as strategic uses of information. In addition, a fair portion of the data held by universities is subject to regulation. These latter factors — centralization of IT,

63 Paul P. Tallon et al. The Information Artifact in IT Governance: Toward a Theory of Information Governance, $30 \mathrm{~J}$. MGMT. INFO. SYS., Winter 2013-14, at 141.

$64 \quad$ Vasant Raval and Greg Dyche, Seven Myths of Information Governance, 4 ISACA J. 1 (2012).

65 Tallon, supra note 63. 
interest in innovation, information subject to regulation-may help information governance, but all told, a university is likely to face significant challenges in implementing information governance.

Second, consider an architectural and civil engineering firm with 100 employees. This firm is highly focused on customer satisfaction and innovation. Its IT is centralized and standardized. The firm is small enough that there are few silos, although the human resources and finance departments each have their own ways of doing things. Services offered by the firm are not particularly diverse even though they handle projects of varying size. Most employees are aware of data growth issues and value a streamlined organization, but they also know it is important to keep records to document safety measures and design decisions. Compared to the university, the engineering firm is nimble and organized around a single purpose. It will face fewer challenges in implementing information governance.

Experts largely agree that information governance requires buy-in, and preferably direction, from the top of the organization. Information governance does not directly generate revenue; funding will need to be thoroughly justified and understood by the very highest echelons of an organization. ${ }^{66}$ In addition, information governance - in both implementation and continual application-must be independent of any one unit and cut across boundaries within an organization. Information decisions must be made with the organization's best interests in mind rather than the interests of individuals or departments within the organization. ${ }^{67}$

A top-down approach to information governance brings together a team of leaders from key areas such as compliance, legal, IT, marketing, and operations. Together, these stakeholders and stewards work "to understand how each of them attaches value to their information, as well as understanding the life cycle of that information. ... By building consensus and understanding, stakeholders will appreciate how their own specific needs impact each of the other groups and influence the overall information governance strategy.”68 Top-down implementation of information governance is particularly effective at taking the holistic view of information that lies at the heart of information governance. Top-down approaches make the most costeffective use of outside consultants, happen more quickly, and leave fewer areas of duplication and overlapping effort. ${ }^{69}$

On the other hand, the top-down approach to information governance may contribute to "analysis paralysis"- so much to do that no one knows where or how to start. The size and complexity of an enterprise-wide project may be overwhelming and a bottom-up approach may be more feasible. ${ }^{70}$ Small projects can be undertaken and then expanded to create the larger framework that will eventually support

\footnotetext{
66 Mintzer, supra note 24.

67 SEDONA CONFERENCE, supra note 4, at 8.

68 Peter Mullens, Information Governance - The top-down approach, BARRACUDA (Nov. 5, 2014), https://blog.barracuda.com/2014/11/05/information-governance-the-top-down-approach/ [http://perma.cc/AAD29XXD].

69 Id.

$70 \quad$ Raval and Dyche, supra note 64.
} 
an enterprise-wide system. ${ }^{71}$ For example, Joe Garber, Vice-President of Information Governance for HP, writes that in cleaning up legacy data

[o]rganizations can start small, focusing on a specific repository, department, or geography. This allows them to clean up legacy information quickly and without having to go through the hassle of getting everyone from every department or business unit to agree on policies and procedure. Perhaps more important, it allows them to realize tangible savings quickly, so they can make a business case for future projects based on facts. In short, information governance is no longer a "boil the ocean" proposition. ${ }^{72}$

Christian P. Walker, an information systems consultant, writes about using guerilla tactics to introduce information governance into clients' projects. With one client, he established good information governance practices within individual projects. These practices included sending links to documents rather than attachments, using versioning instead of iterative copies, labeling work consistently, applying retention and deletion schedules, and securing content. ${ }^{73}$ The organization's vice-president of IT noticed, and asked how to implement information governance across the enterprise. ${ }^{74}$ Reflecting on this experience, Walker explained that “[s]ometimes you've just got to sneak IG into your client's projects the same way you sneak veggies into a recalcitrant child's diet." 75

A bottom-up, small project approach to information governance may also result in fewer disruptions of current practices and deal more immediately with real problems. ${ }^{76}$ It may also avoid misunderstandings, unsuitable policies, and resistance that may follow when information governance is handed down from on high. For information governance to work, policies must suit needs, and everyone must accept accountability for governance over the long haul and bear responsibility. ${ }^{77}$ Information governance is a shared undertaking, and involving data stakeholders is key. The CIO of University of Washington Medical Center puts it well:

We have a master data map that looks at our six major areas of data.... We have a data management committee whose members are the owners of these six areas. They set the policies and decide what is core and peripheral...consult with administrators as to how

\footnotetext{
$71 \quad$ Id.

72 Joe Garber, It will cost you if you don't have an information governance strategy, 21 LEGALTECH NEWS, June 2015, at 41, 42.

73 Christian P. Walker, Guerrilla Tactics - IG whether they want it or not, INFO GOV GUERRILLA (Sept. 29, 2014), https://christianpwalker.wordpress.com/2014/09/29/ig-guerrilla-tactics/ [http://perma.cc/ND96-T4WR].

$74 \quad I d$.

$75 \quad I d$.

76 Peter Mullens, Information Governance - the bottom-up approach, BARRACUDA (Nov. 19, 2014), https://blog.barracuda.com/2014/11/19/information-governance-the-bottom-up-approach/ [http://perma.cc/ZT2W$87 \mathrm{NU}$.

77 Debra Logan, What Is Information Governance? And Why Is It So Hard?, GARTNER (Jan. 11, 2010), http://blogs.gartner.com/debra_logan/2010/01/11/what-is-information-governance-and-why-is-it-so-hard/ [http://perma.cc/D9ND-3XFU].
} 
information is used. We also have a policy document that sets out roles for data custodians, stewards, and owners. Even if I'm the CIO, I don't own the institution's data....But being responsible for data integrity, storage, and security, I have a role as the main data steward. My job is executing policy. ${ }^{78}$

This statement highlights not only user involvement in policy-setting but also shared oversight and the creation of ownership/stewardship rights and responsibilities. Tallon refers to these as "structural practices." 79 In addition to these structural practices, successful information governance requires significant "relational practices" such as instruction, communication regarding user needs, and feedback on the effectiveness of policies and procedures. ${ }^{80}$

This idea that both structural and relational practices are necessary highlights the fact that, in the end, comprehensive information governance requires both top-down and bottom-up input and commitment. Those with enterprise-wide accountability can provide big-picture analysis, insight into organizational goals, and leverage to see that goals are actually achieved. Those with hands-on experience with and responsibility for the various kinds of information bring detailed knowledge about data content and use along with the ability to actually execute procedures to the table. If either the top-down or bottom-up trajectory is missing, information governance will be more difficult to achieve.

\section{THE IMPORTANCE OF INFORMATION GOVERNANCE INSTRUCTION}

Although there are still knowledge and skills gaps among attorneys regarding e-discovery, ${ }^{81}$ some lawyers have developed considerable expertise and others are beginning to get up to speed. Law firms are starting to offer more e-discovery services in-house and investing more money and expertise in e-discovery technology. According to the Law Firm e-Discovery Strategy Survey published in April 2015 by HBR Consulting, "[a] law firm's capability to provide e-discovery services has gone from a novelty to a business necessity." ${ }^{82}$ This is echoed in a 2015 advisory opinion from the California State Bar's Standing Committee on Professional Responsibility and Conduct stating that the professional obligation of competency requires facility with e-discovery for any attorney dealing with litigation. ${ }^{83}$

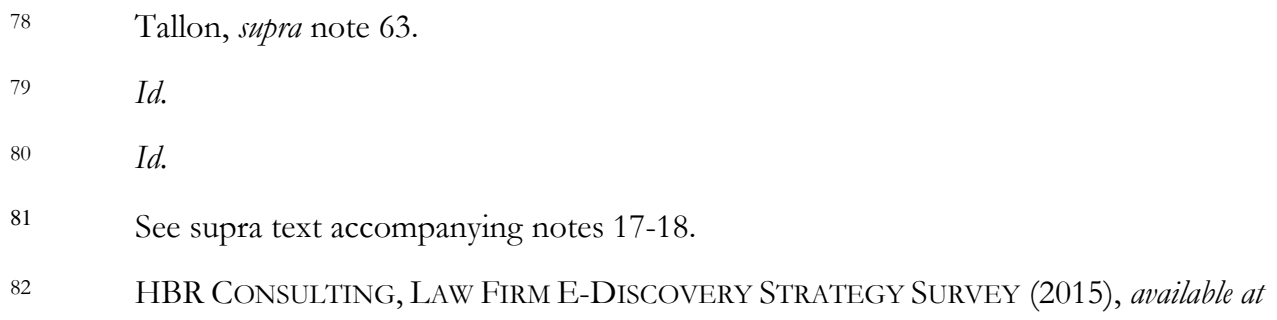

http://www.hbrconsulting.com/downloads/HBR_LDC_Law\%20Firm_EDiscovery_EXECUTIVE\%20SUMMARY_S urvey_Results_May_2015.pdf [http://perma.cc/2DGR-67JY]; HBR Releases Results of Law Firm e-Discovery Strategy Survey, BusinessWire (May 27, 2015, 12:36 PM EDT), http://www.businesswire.com/news/home/20150527006283/en/HBR-Releases-Results-Law-Firm-e-DiscoveryStrategy\#.VXIInNJVhHw [http://perma.cc/4NXN-J6VZ].

83 State Bar of Cal. Standing Comm. on Profl Responsibility \& Conduct, Formal Op. No. 2015-193 (2015)

("Attorneys attorney handling e-discovery should be able to perform (either by themselves or in association with competent co-counsel or expert consultants) the following:

- initially assess e-discovery needs and issues, if any; 
As the preceding sections explain, e-discovery cannot be dealt with in a vacuum. ${ }^{84}$ The Law Firm eDiscovery Strategy Survey states that "assisting clients with Information Governance challenges" is an area where law firms can expand service offerings. Basri and Mack point out that counsel with expertise will be well-positioned to manage not only e-discovery but also "broader information governance activities for the corporation.”85

Education is key to creating this competence. In their treatise eDiscovery for Corporate Counsel, Carole Basri and Mary Mack assert that "this means formal law school training for law students. ...[T]he demand for lawyers who understand the law and technology...will outstrip the supply of qualified professionals.” 86 In a similar vein, Chris Gallagher, an expert on the e-discovery industry and an adjunct professor at Touro College of Law, writes that "eDiscovery and [other information technology-based] usable skills will ensure that recent law school graduates will be an immediate value to their clients, saving them both time and money.",87

It is likely that demands for lawyers with information governance expertise will only increase as corporations face greater information obligations. Charles Ragan, a commercial litigator, draws a

- implement/cause to implement appropriate ESI preservation procedures;

- analyze and understand a client's ESI systems and storage;

- advise the client on available options for collection and preservation of ESI;

- identify custodians of potentially relevant ESI;

- engage in competent and meaningful meet and confer with opposing counsel concerning an e-discovery plan;

- perform data searches;

- collect responsive ESI in a manner that preserves the integrity of that ESI; and

- produce responsive non-privileged ESI in a recognized and appropriate manner.”).

$84 \quad$ See supra Parts II through V.

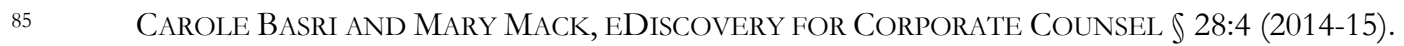

$86 \quad I d$.

87 Chris Gallagher, eDiscovery: The Crucial Next Step in Law School Curriculum, BLOOMBERGBNA LEGAL COMMUNITIES: BIG LAW Business (June 5, 2015), https://bol.bna.com/ediscovery-the-crucial-next-step-in-law-schoolcurriculum/ [http://perma.cc/U3UV-8JNE]. Many commentators in the legal blogosphere have echoed the need for instruction in e-discovery and other information technology related skills in the law school curriculum (and elsewhere) as well. See, e.g., Shannon Capone Kirk and Kristin G. Ali, "Teach Your Children Well" - A Case for Teaching E-Discovery in Law Schools, E-DiSCOVERY TEAM, http:/ / e-discoveryteam.com/school/\%E2\%80\%9Cteach-your-childrenwell $\%$ E2\%80\%9D-a-case-for-teaching-e-discovery-in-law-schools/ [http://perma.cc/9BKU-SHGV] (last visited June 5, 2015); Hilary Daninhirsch, E-discovery training crucial to a full legal education, INSIDE COUNSEL (June 16, 2014), http://www.insidecounsel.com/2014/06/16/e-discovery-training-crucial-to-a-full-legal-educa [http://perma.cc/4EMLJ6SC]; Michael Fitzgerald, 14 Reasons Law Schools Must Teach Tech, INFO. WEEK, (July 9, 2013),

http://www.informationweek.com/mobile/mobile-devices/14-reasons-law-schools-must-teach-tech/d/d-id/1110682? [http://perma.cc/NH5A-2ASD]. See also Richard Granat and Marc Lauritsen, Teaching the Technology of Practice: The Top 10 Schools, 40 LAW PRAC., July-Aug. 2014, at 44, available at

http://www.americanbar.org/publications/law_practice_magazine/2014/july-august/teaching-the-technology-ofpractice-the-10-top-schools.html [http://perma.cc/KTE3-A9GW]. 
connection between the Delaware Chancery Court's opinion in In re Caremark International, Inc. Derivative Litigation, ${ }^{88}$ which expanded the oversight duty of a corporate board of directors to include ensuring compliant management of records to prevent corporate losses, and the need for information governance. ${ }^{89}$ In light of data security breaches and the rising costs of e-discovery, Ragan's point adds considerable weight to the argument that law students need instruction in information governance.

Similarly, law firms are under pressure from clients to demonstrate that they "maintain[] high quality internal information governance...strategies and practices." ${ }^{90}$ Clients want assurances that law firms are equipped to address data security and privacy concerns. Lawyers need to be able to discuss information governance knowledgeably and to show that their own practice is engaged in rigorous information governance.

A few schools are already including information governance in their e-discovery or "technology of law” curricula. ${ }^{91}$ Gallagher notes that

[c]lasses that follow the Electronic Discovery Reference Model (EDRM) ${ }^{92}$ beginning with Information Governance would give students real world understanding of the flow of data. Corporations are working harder than ever to balance legal and regulatory obligations with business efficiency and a goal of reducing the cost of electronically stored information (ESI), limiting liability, and increasing process efficiency. ${ }^{93}$

Nonetheless, the vast majority of schools are not teaching information governance, even at a time when students are searching for ways to differentiate themselves in a tight job market. ${ }^{94}$ To ameliorate this situation, more law librarians and other legal educators need not only the basic knowledge about information governance provided in the previous sections but also ideas about how it can be taught.

\section{TEACHING INFORMATION GOVERNANCE}

\footnotetext{
88 In re Caremark Int'l Inc. Derivative Litigation, 698 A.2d 959 (Del. Ch. 1996)

89 Ragan, supra note 26 , at $\mathbf{9 1 1 - 1 5 .}$

90 Erin E. Harrison, The Firm of the Future: Utilizing IG Assessments to Meet Clients' Needs, LEGALTECH NEWs (Aug. 31, 2015), http://www.legaltechnews.com/id=1202736089998 [http://perma.cc/L6P3-5NAY].

91 The University of Minnesota Law School offers a seminar in information governance taught by Charles Ragan. Course Details, UNIVERSITY OF MINNESOTA LAw SCHOOL, https://www.law.umn.edu/current/alphabetical-courselist/details.html?courseNumber=6705 [http://perma.cc/7NJF-TWHJ]. The Cardozo School of Law is offering a program called the Cardozo Data Law Initiative that includes information governance in its curriculum. Cardozo Data Law Initiative, CARDOZO LAW, http://www.cardozo.yu.edu/CDLI [http://perma.cc/7KU8-7LT6]. Similarly, Vanderbilt Law School offers a course entitled Electronic Discovery and Information Governance. Course Information: Electronic Discovery and Information Governance, VANDERBILT LAW SCHOOL, https://law.vanderbilt.edu/courses/304 [http://perma.cc/3F96-PN2X]. 
Information governance has a unique manifestation in every enterprise, and, to an extent, teaching information governance is about communicating a mindset and a deep understanding of information and its uses. It is not about a specific set of skills or knowledge. This makes the topic ill-suited for the lectureand question-based approaches typical of law school classrooms. Instead, it invites a hands-on, active learning pedagogy such as problem-based learning or the case-study method. These approaches fit well with the American Bar Association's accreditation requirement for experiential learning instituted in the 2014-15 standards. ${ }^{95}$

Problem-based learning (PBL) inverts the traditional approach of providing substantive material to students and posing questions to test their comprehension and retention. In PBL, the teacher presents students with a problem, a real-life (or close to) situation. The problem should be somewhat messy_-illstructured" as the pedagogical literature terms it. ${ }^{96}$ The problem should not have one pat answer but rather pose decision points with multiple possible answers. PBL lets students explore and learn from realistic complexities. ${ }^{97}$

Students, typically working in small groups, chart their own course of learning as they investigate the problem. The teacher engages with the students in the role of tutor and facilitator. Once the students reach solutions, their groups spend time reflecting on their efforts. They consider what they have learned, how they learned it, and what they might have done differently. They consider how to apply what they learned in one situation to other situations. In short, problem-based learning offers students the opportunity to learn substantive material, its application to real problems, and problem-solving skills all at the same time while maintaining ownership over their own learning process. ${ }^{98}$

See Standards 303(a)(3) (Curriculum) and 304 (Simulation Courses and Law Clinics). American Bar Association, ABA Standards and Rules of Procedure for Approval of Law Schools (2014-2015).

96 David H. Jonassen and Woei Hung, All Problems are Not Equal: Implications for Problem-Based Learning, in EsSENTIAL REAdings in PROBLEM-BASED LEARNING: EXPLORING AND EXTENDING THE LEGACY OF Howard S. BARROWS 17, 21-15 (Andrew Walker et al. eds., 2015).

\footnotetext{
$97 \quad I d$.

98 See, e.g., John R. Savery, Overview of Problem-Based Learning: Definitions and Distinctions, in ESSENTIAL READINGS IN PROBLEM-BASED LEARNING: EXPLORING AND EXTENDING THE LEGACY OF HOWARD S. BARROwS 5 (Andrew Walker et al. eds., 2015). PBL's development and success in medical schools and wider adoption in other disciplines at all levels, including law, has been thoroughly documented elsewhere. See generally EssEntial READINGS IN Problem-BASED LEARNING: EXPLORING AND EXTENDING THE LEGACY OF HOWARD S. BARROWS (Andrew Walker et al. eds., 2015); José A. Amador et Al., The Practice of Problem-Based Learning: A Guide to Implementing PBL in the College Classroom (2006); The Power of Problem-Based Learning (Barbara J. Duch et al. eds., 2001); Christine Ver Ploeg and Jim Hilbert, Project-Based Learning and ADR Education: One Model for Teaching ADR Students to Problem Solve for Real, 11 AppalaCHIAN L.J. 157 (2011-12); Keith H. Hirokawa, Critical Enculturation: Using Problems to Teach Law, 2 DreXel L. Rev. 1 (2009-10); Shirley Lung, The Problem Method: No Simple Solution, 45 WillametTe L. Rev. 723 (2008-09); Cath Sylvester et al., Problem-based learning and clinical legal education: What can clinical educators learn from PBL?, 4 InT'L J. Clinical Legal Educ. 39 (2004); Fiona Martin, Using a Modified Problem Based Learning Approach to Motivate and Enhance Student Learning of Taxation Law, 37 LAW TEACHER 55 (2003). Given the wide availability of information on problem-based learning, the focus here need only be on designing a PBL unit on information governance.
} 
One drawback of using problem-based learning to teach information governance is that PBL, at least in theory, embraces an open inquiry model in which students decide what the questions are and how to seek answers. ${ }^{99}$ Conceivably, students could pursue avenues that do not help them learn about information governance.

The case-study method ${ }^{100}$ provides a more structured and guided inquiry than PBL and may be more appropriate depending on learning objectives and time considerations. ${ }^{101}$ The case-study method referred to here is not the use of appellate cases to discern legal principles as in the typical law school course. Instead it is the business school approach in which students are presented business situations and dilemmas based on real companies and background materials to help them understand these dilemmas. Students take on the role of decision-makers and explore through discussion, debate, and analysis what could or should be done and what the consequences might be. Students then examine what decisions were actually made and how those decisions played out. ${ }^{102}$

An information governance project lends itself well to either of these active learning approaches. ${ }^{103}$ Applicable learning objectives might include:

- Describe complexity of information assets and systems in today's businesses.

- Articulate the purpose and benefits of information governance.

- Explain how information governance can work.

- Identify and analyze specific risk areas and areas for improvement in business under study.

- Develop recommendations for implementation of information governance with emphasis on risk areas.

\footnotetext{
99 It should also be noted that PBL purists urge that this pedagogical method should not be used piecemeal but rather only across entire courses or even curricula. See Savery, supra note 97. Nonetheless, instructors have documented success with smaller PBL units. See, e.g., Amador, supra note 97.

100 It is also called simply the "case method" but this creates even more opportunity for confusion with the typical law school classroom approach.

101 See M. Srinivasan et al., Comparing problem-based learning with case-based learning: Effects of a major curricular shift at two institutions, 82 ACADEMIC MEDICINE, Jan. 2007, at 74.

102 For more detailed information on the business school case study method and its use in legal education, see Michelle M. Harner and Robert J. Rhee, Deal Deconstructions, Case Studies, and Case Simulations: Toward Practice Readiness with New Pedagogies in Teaching Business and Transactional Law, 3 AM. U. Bus. L. REV. 81 (2014); Michelle M. Harner and Robert J. Rhee, Innovation in Teaching LLC: Teaching LLCs Through a Problem-Based Approach, 71 WASH. \& LEE L. REV. 489 (2014); Judy Gedge, Should Deficiency Judgments be Banned? Teaching Materials Designed to Promote an Informed Student Debate, 19 J.L. Bus. \& ETHICS. 65 (2013); Celeste M. Hammond, Borrowing from the B Schools: The Legal Case Study as Course Materials for Transaction Oriented Elective Courses: A Response to the Challenges of the MacCrate Report and the Carnegie Foundation for Advancement of Teaching Report on Legal Education, 11 TransaCTIONS 9 (2009); Todd D. Rakoff and Martha Minow, A Case for Another Case Method, 60 VAND. L. REV. 597 (2007); Bradley T. Borden, Using the Client-File Method to Teach Transactional Law, 17 CHAP. L. REV. 101 (2013).

103 Active learning is a broad term referring to activities that demand more of learners than merely listening to someone speak and taking notes. The purpose of active learning is to provide opportunities for learners to become engaged in the material and take responsibility for their own learning.
} 
- Prepare and give a presentation (or prepare written report) explaining information governance, its importance to the business, and recommended implementation to corporate officers.

With these objectives in mind, the instructor can craft a problem scenario in which a business has a variety of information assets in various forms and locations with different purposes and stewards. Consider the example above of the architectural firm. A scenario could be crafted in which this architectural firm is sued for failure to use low-e glass in the windows of an apartment building, making the apartments inefficient in warm weather. ${ }^{104}$ In the course of discovery, the lawyers (students) identify issues with the firm's use of data. Some possible issues include: employees who sometimes use personal computers for work; computers that have been wiped without appropriate backup and analysis of their contents; employees who have left the firm and taken their laptops with them; backup systems that are not always run on schedule; records retention schedules that are nonexistent or not followed; data stuck in legacy systems; a lack of guidelines for email storage and retention; no system for preserving work-related text messages; and scattered responsibility for regulatory compliance. This "ill-structured" problem becomes the basis for the students' research into information governance and development of a client proposal that identifies problem areas, and recommends and explains implementation of information governance.

In a PBL approach, the groups of students can be expected to conduct their own research and learn how to look beyond the legal sources such as cases and statutes with which they are familiar. This may prove too time-intensive, though, due to the large number of articles and business blog posts on information governance. Using a more guided-inquiry approach, the instructor can create an electronic library or bibliography for students to draw on. ${ }^{105}$ Students would still have to analyze and sift the materials but will be prevented from going too far astray.

For the case-study approach, the instructor can select a real-world information governance problem in which the company's actual solutions are documented. For example, in the last decade, Intel revised its management of information from simple protection of data to a "protect-to-enable" governance approach. Both the before and after governance structures and the issues addressed are discussed in a 2013 article in MIS Quarterly Executive. ${ }^{106}$ An instructor could assign the first half of the article to set the scene and establish the problems. Students can then use information governance materials, and perhaps more information about Intel, to discuss solutions. The second half of the article can then be used to illustrate what decisions were actually made and prompt discussion of how those decisions have played out.

With either problem-based learning or a case-study approach, students will be immersed in realistic issues, and expected to explore information governance literature and propose solutions—all designed to simulate a real-world situation arising out of the e-discovery context.

104 See Fred A. Berstein, Lawsuit Suggests New Liability for Architects, ArCHITECTURAL RECORD (Aug. 20, 2014), http://archrecord.construction.com/news/2014/08/140820-Lawsuit-Suggests-New-Liability-for-Architects.asp [http://perma.cc/EAL3-BVVV].

105 See Appendix A for a list of suggested materials.

106 Paul P. Tallon et al. The Evolution of Information Governance at Intel, 12 MIS QUARTERLY EXECUTIVE, Dec. 2013, at 189. 


\section{CONCLUSION}

Implementing information governance is difficult, especially given the exponential growth trajectory of information, but the effort pays off. Information governance leads to reductions in risks, errors, costs, and lawsuits and improves decision-making, customer satisfaction, and effective use of data. ${ }^{107}$ In its Commentary on Information Governance, published in December 2013, the Sedona Conference provides telling examples of how information governance can benefit different types of organizations in different ways. ${ }^{108}$ A business such as Wal-Mart that focuses on efficiency and cost control may benefit from information governance because it helps streamline information flows and reduces unnecessary data storage. An organization in a highly regulated field such as health insurance or finance may benefit from the assurance of compliance supplied by information governance. An organization that depends on creativity such as a graphic design firm or a marketing firm may find that information governance maximizes the accessibility and usability of its information assets. ${ }^{109}$ For an organization of any kind, it is also the new reality that people outside the organization—judges, regulators, insurers, suppliers, customers, clients, and future hires-may expect information governance. ${ }^{110}$

Trends in business management come and go, and information governance has its detractors who claim it is already passé thanks to cheap storage and powerful search algorithms. ${ }^{111}$ Nonetheless, the purposes and principles of information governance-regardless of what it is called or exactly how it is defined-are both timeless and timely. As Joe Garber, Vice-President of Information Governance for HP, explains, "With growing enterprise data posing so many challenges_-and perhaps holding so much untapped valueorganizations simply can't wait any longer.... The time to act is now...."112 The time for law schools to prepare students for this demand is now as well.

107 Id. Tallon cautions that the positive effects of information governance were easier to see in mid-level results than at the firm-level, e.g., it is easier to see fewer errors than to correlate information governance to greater profitability.

108 SEDONA CONFERENCE, supra note 4, at 5-6.

$109 \quad$ Id.

110 See BARClay T. Blair, MAKING THE CASE FOR INFORMATION GOVERNANCE: 10 REASONS WHY INFORMATION GOVERNANCE MAKES SENSE 5-10 (2011), http://barclaytblair.com/2011/08/22/making-the-case-forig-ebook/.

111 See, e.g., Losey, supra note 51.

112 Garber, supra note 72, at 41. 


\section{APPENDIX A:}

\section{MATERIALS ON INFORMATION GOVERNANCE FOR STUDENT PROJECT}

1. SEDONA CONFERENCE, COMMENTARY ON INFORMATION GOVERNANCE (2013), available at https://thesedonaconference.org/publication/The\%20Sedona\%20Conference\%C2\%AE\%20Com mentary\%20on\%20Information\%20Governance (providing a comprehensive but manageable explanation of information governance with strong connections drawn to the legal considerations).

2. Alan MacClellan, Information Governance AND AsSURANCE: RedUCing Risk, PROMOTING POLICY (2014) (discussing the essential information knowledge and skills necessary in information governance).

3. Robert F. SMALlwOOd, InFORMATION GOVERnANCE: CONCEPTS, STRATEGIES, AND BeST PRACTICES (2014) (covering all aspects of information governance from big picture to best practices).

4. BARCLAY T. BLAIR, MAKING THE CASE FOR INFORMATION GOVERNANCE:10 REASONS WHY IG MAKES SENSE (2010), http://barclaytblair.files.wordpress.com/2011/08/making-the-case-forinformation-governance-barclay-t-blair.pdf [http://perma.cc/J3AN-BFHX] (presenting the necessity of information governance)

5. Charles R. Ragan, Information Governance: It's a Duty and It's Smart Business, 19 RICHMOND J. L. \& TECH. 12 (2013) (explaining information governance and its importance).

6. Bennett B. Borden and Jason R. Baron, Finding the Signal in the Noise: Information Governance, Analytics, and the Future of Legal Practice, 20 RichMOND J. L. \& TECH. 7 (2014) (discussing the value of information governance in making information more usable in legal contexts).

7. How the Information Governance Reference Model (IGRM) Complements ARMA International's Generally Accepted Recordkeeping Principles (GARP®), EDRM (Dec. 2011), http://www.edrm.net/resources/edrm-white-paper-series/igrm-garp [http://perma.cc/599W-REU6] (detailing the relationship between the IGRM and GARP with a focus on assessing the maturity level of an organization's information governance).

8. Paul P. Tallon et al. The Evolution of Information Governance at Intel, 12 MIS QUARTERLY EXECUTIVE, Dec. 2013, at 189 (discussing implementation of information governance at Intel, moving the company from a "protect" mindset to a "protect-to-enable" mindset with regard to its data).

9. Kristin Weber et al., One Size Does Not Fit All-A Contingency Approach to Data Governance, 1 ACM J. DATA \& INFO. QUALITY, June 2009, at Art. 4 (applies concepts from IT governance to data or information governance).

10. Harry Pugh, Information Governance: A Practical Approach for the Dodd-Frank Era, 29 WALL STREET \&TECH., Feb. 2011 (focusing on the need for information governance in financial institutions, emphasizing defensible disposal and records management). 
11. Mario Silic and Andrea Beck, Factors Impacting Information Governance in the Mobile Device Dual-Use Context, 23 RECORDS MGMT. J. 73 (2013) (focusing on issues arising from mobile technologies and bring-your-own-device policies).

12. Juerg Hagmann, Information Governance--Beyond the Buzz, 23 RECORDS MGMT. J. 228 (2013) (investigating information governance from the perspective of someone familiar with records management practices, and emphasizing information governance's broader holistic perspective).

13. Deborah H. Juhnke, Four Steps for Conquering Information Chaos, InFo. MGMT., Mar./Apr. 2013, at 35 (focusing on accountability, assessment, analysis, action, and audit to achieve information governance).

14. Sam McCollum, A Roadmap for Effective Information Governance, INFO. MGMT., Jan./Feb. 2013, at 27 (discussing thirteen steps in developing a "strategic information management" plan and roadmap in the context of information governance).

15. Debra Logan, What is Information Governance? And why is it so hard?, GARTNER (Jan. 11, 2010), http://blogs.gartner.com/debra_logan/2010/01/11/what-is-information-governance-andwhy-is-it-so-hard/ [http://perma.cc/D9ND-3XFU] (offering a quick read on information governance basics).

16. Debra Logan, How Can Governance Succeed?, GARTNER (Jan. 25, 2010), http://blogs.gartner.com/debra_logan/2010/01/25/how-can-governance-succeed/ [http://perma.cc/2BBA-9JPP] (following up on Logan's earlier post with a more in-depth look at what is required for information governance to be successful).

17. Christian P. Walker, Principles of Holistic Information Governance, INFO Gov GUERRILLA (Apr. 1, 2013), https://christianpwalker.wordpress.com/2013/04/01/principles-of-holistic-informationgovernance/ [http://perma.cc/4WYF-GVC7] (providing a quick checklist of considerations when undertaking information governance). 